\title{
Review
}

Intervirology

\section{Survival of Viruses in Water}

\author{
Anthony Pinon Michèle Vialette \\ Institut Pasteur de Lille, Lille, France
}

\section{Keywords}

Survival - Inactivation - Water - Liquid medium - Resistance . Inactivation rate $\cdot$ Viral inactivation model

\begin{abstract}
Water, a frequent vehicle for the transmission of viruses, may permit their survival, but many environmental factors will have an adverse effect on the viral population. Risk evaluation requires identification of these factors and assessment of the inactivation rate of infectious viruses. A higher temperature means a faster reduction of the viral population, as do increased sunlight, higher antimicrobial concentration, or higher oxygen levels. Another documented impact is linked to the presence of indigenous microbial populations: virus survival is higher in sterile water. Environmental factors inactivate viruses through direct or indirect action on one part of the viral structure: genome, capsid, or envelope if present. Viral populations also have resistance mechanisms, generally involving physical shielding from adverse effects; such protective behaviors include aggregation, adhesion, or internalization inside living structures. Because of these phenomena, inactivation kinetics may deviate from traditional log-linear shapes. It is therefore important to account for all factors that may impact on survival, to carefully design experiments to ensure sufficient data, and to select the right modelling approach. Comparison between studies is difficult. It is suggested that laboratory studies include standard
\end{abstract}

\section{KARGER}

() 2018 S. Karger AG, Basel

E-Mail karger@karger.com

www.karger.com/int conditions of water, and analyze the impact of different factors as precisely as possible. Larger studies in natural environments, though more difficult, are also much needed.

๑) 2018 S. Karger AG, Basel

\section{Introduction}

The transmission of pathogens occurs through various means, which are not limited to direct person-to-person contagion. Pathogens, including viruses, are able to spread and be transmitted by environmental routes. Vehicles include air, inert surfaces, or liquid media. Most viruses concerned by liquid transmission will pass through water, including enteric viruses (the fecal-oral route frequently includes water as one of the vehicles), viruses affecting aquatic animals or waterfowls, and plant viruses, etc. This underlines the importance of studying the fate of viruses in water.

Virtually all forms of water are concerned by viral contamination: surface freshwater such as lakes and rivers, groundwater, estuary and marine waters, or even ice [1]. In the USA, $72 \%$ of groundwater sites have been found to be positive for the presence of enteric viruses [2]. Contamination occurs through various means, a significant part of which is linked to human activities, including the disposal of untreated sewage, reuse of incompletely treated effluent, use of animal waste as manure, etc. Exposition 
to contaminated water may subsequently occur through numerous ways, linked to one of innumerable uses of water, such as drinking, irrigation, aquaculture, recreational activities, etc.

Viruses are obligatory intracellular parasites: when viral particles are suspended by themselves in water, they may only survive or die, which means that the viral count will stay the same or decrease over time. Considering the high numbers of viral particles shed by infected individuals (for example, $1 \mathrm{~g}$ of feces from an infected individual may contain as high as $10^{10}$ rotaviruses [3]) and the low infectious dose of some viral diseases (estimated at 1-10 particles for some viruses [4]), gaining knowledge on the ability of viruses to survive in water is particularly important.

Noroviruses and related viruses are considered to be the major cause of waterborne diseases worldwide [4]. Together with other enteric viruses, they are one of the main causes of diarrhea, which has been ranked as the world's leading cause of mortality in children under 5 years of age. Other frequently reported human pathogens associated with water transmission include adenovirus, rotavirus (responsible for 527,000 deaths of children under 5 years of age in 2004 [5]), and hepatitis A virus, along with a number of other enteric viruses, such as coxsackievirus, echovirus, reovirus, astrovirus, etc. Influenza viruses or other viruses linked to aquatic animals or plants are also transmitted through water.

While numerous authors have studied the survival of viruses in water, their objectives in performing these studies are variable. Likewise, many different experimental approaches have been chosen. In the following sections, we initially describe the various goals and methods of viral persistence and inactivation studies. This is followed by an examination of the impacts of factors affecting virus survival. Then, subsequent sections deal with the mechanisms responsible for viral inactivation, as well as focusing on the strategies of viruses for resistance to adverse environmental effects. Finally, some concluding remarks and possible ideas for further studies are put forward.

\section{Experimental Studies: Goals, Methods}

The main reason for studying virus survival in water is an issue of risk evaluation. Many authors have tried to assess the ability of pathogenic viruses to survive in a given environment to which human, animal, or vegetal life is exposed. Since water contamination is known to occur, whether or not viruses are able to survive long enough and in sufficient amounts to reach and infect a susceptible host represents a crucial issue of public health.

A related goal in viral survival studies lies in the evaluation of the efficiency of control measures. Water disinfection is routinely used to provide potable water, and reinforced measures may be used temporarily in relation to a specific threat (either increased pollution due to extreme natural causes or suspicion of intentional release of biowarfare agents). In such cases, the efficiency of water treatments needs to be evaluated against viral agents [6].

Water quality is frequently assessed by the detection of bacterial indicators, which are supposed to represent the overall degree of water contamination by pathogenic bacteria. However, viruses are different, and their behavior may not be adequately represented by that of bacteria. Therefore, some authors have proposed the use of indicator viruses, which would be representative of the viral behavior in water. Useful indicators should be amongst the most resistant ones, to ensure that control measures are efficient on a large range of viruses: if no indicator is detected, one should be able to assume with a high degree of certainty that no viral pathogen is present either. It is thus important to characterize the survival abilities of candidate viral indicators, and to compare them to those of pathogenic viruses.

Bacteriophages are viruses that target bacteria. As such, they may be used as biological weapons against certain types of pathogenic bacteria. One example is the use of bacteriophages against such bacteria as Aeromonas salmonicida or Vibrio parahaemolyticus, which are responsible for fish diseases in aquaculture [7]. In this context, it is important to assess the survival of bacteriophages in water, since it will have an impact on their efficiency.

While a majority of authors use infectious titers to quantify virus survival, some have instead used genome quantification by quantitative (q)PCR [8]. In spite of the high performance of qPCR in terms of sensitivity, specificity, or reproducibility, it is not adapted to survival studies. Indeed, genome fragments targeted by PCR may remain relatively unharmed by adverse factors rendering the virus noninfectious [9]. Virus survival is systematically overestimated by qPCR methods, as demonstrated by many studies $[10,11]$. While qPCR may have useful applications in assessing that the virus has been present in the environment, it may not be used to evaluate the impact of environmental factors on virus survival or the risk for water users. A potential problem with such approaches may be that chemical products would appear inefficient for virus destruction, and thus higher 
doses would be used, thereby creating environmental hazards.

There is a rather large spectrum of studied viruses. Obviously, the goal of the study will determine which virus needs studying. For example, several authors tried to find a way of assessing the resistance of the nonculturable human norovirus by using culturable surrogates, such as murine norovirus or feline calicivirus [12, 13]. Risk evaluation targets viruses that represent pressing issues linked to waterborne contaminations: enteric viruses such as adenovirus are a good example $[14,15]$. There appears to be an evolution in the perceived or real risk that some viruses pose. As an example, the survival of poliovirus in water was historically extensively studied [16-19] before the number of studies declined in recent years in parallel with the eradication of the disease worldwide. On the other hand, there has been an increase in respiratory diseases linked to viruses carried by waterfowl, such as influenza $[1,20,21]$, and studies on these viruses have been increasingly numerous. Likewise, following the terrorist threats of the early 2000s, more studies have been dedicated to potential biowarfare agents $[6,22]$.

Similar viruses have been studied in various types of water. Viruses such as poliovirus or bacteriophage MS2 have been studied in groundwater [3, 14], in seawater [23, $24]$, or in tap water $[25,26]$. Researchers generally use artificially contaminated water, which is not necessarily representative of actual threats in the studied environment. However, it is important to compare behaviors of viruses in diverse waters, since their characteristics are highly variable, and may indeed produce different results.

\section{Factors Affecting Virus Survival}

In the absence of host cells, viral populations in the environment may only decrease or remain stable. Therefore, when considering the evolution of a viral population with time, varying an environmental factor will eventually produce a reduction in viral counts. The evaluation and analysis of the shape and intensity of this reduction represent major objectives of viral inactivation studies.

Temperature has been the most studied factor, and is indeed often recognized as the most influential one $[3,23$, 27]. It has been universally demonstrated that higher temperatures mean faster viral inactivation. At low temperatures above freezing, viruses may survive for extended periods of time, often longer than the duration of the study [18], and sometimes for several years [21]. At higher temperatures, the viral population will be reduced by several orders of magnitude in a few days [28]. Obviously, heating will kill viruses within minutes [20,29]. Freezing temperatures allow viruses to remain stable for several months at least, although an initial decrease may be observed in the first days [1].

Studies of the impact of temperature often focus on 2 or 3 levels, generally including a low temperature (4 or $\left.10^{\circ} \mathrm{C}\right)$, ambient temperature $\left(20-25^{\circ} \mathrm{C}\right)$, and body temperature $\left(37^{\circ} \mathrm{C}\right)$. It is then possible to infer the influence of temperature on viral stability. For example, it has been shown that poliovirus, echovirus, and coxsackievirus populations in seawater were reduced by $5 \log$ units in less than a week at $37^{\circ} \mathrm{C}$, while it took 1 year at $4^{\circ} \mathrm{C}$ in laboratory conditions. In free-flowing ocean water, a 5-log reduction of poliovirus and echovirus occurred in 1 month in summer (water temperature $21-26^{\circ} \mathrm{C}$ ), and in a little more than 2 months in winter $\left(4-16^{\circ} \mathrm{C}\right)$ [23]. In mineral water, poliovirus lost $1 \log$ unit in 330 days at $4^{\circ} \mathrm{C}$, while it took 60 days at $23^{\circ} \mathrm{C}$; hepatitis A virus proved more resistant than poliovirus in similar conditions [18]. Astrovirus in tap water was reduced by $2 \log$ units in 60 days at $4^{\circ} \mathrm{C}$ and 30 days at $20^{\circ} \mathrm{C}$ [30]. Adenovirus in groundwater lost $1 \log$ unit in 132 days at $4^{\circ} \mathrm{C}$, and in 36 days at $20^{\circ} \mathrm{C}$ [14]. A similar 4-log reduction of $\mathrm{H} 5 \mathrm{~N} 1$ in river, lake, or seawater was observed in 5 weeks at $6^{\circ} \mathrm{C}$, and in 3 weeks at 22 or $35^{\circ} \mathrm{C}[31]$. The viral decrease is not always log-linear, however, as an initial stability may be observed in less aggressive conditions [30]. Likewise, small variations of temperature may produce no significant differences in inactivation kinetics [32].

Solar light is another important factor producing viral inactivation, through the action of UV radiation. Viruses survive better in the dark than when exposed to sunlight. Bacteriophage GA in seawater lost 1 log unit in $4 \mathrm{~h}$ when exposed to light simulating winter conditions at $10^{\circ} \mathrm{C}$, and in $15 \mathrm{~min}$ when exposed to light simulating summer conditions at $17^{\circ} \mathrm{C}$ [9]. Infectious hematopoietic necrosis virus in seawater lost $2-3 \log$ units in $3 \mathrm{~h}$ in deep water, and 3-4 log units in $1.5 \mathrm{~h}$ in surface water, corresponding to higher exposure to sunlight [32]. The effect of light is enhanced for longer exposition times or lower turbidity, corresponding to a higher dose of UV exposure [16].

The impact of water salinity has not always been found to be very significant on enteric viruses [23], whereas higher salinity corresponded to significantly faster inactivation of influenza A H1N1 [21].

The presence of an indigenous microbial population has a negative impact on virus survival [33]. Viral inactivation is consistently accelerated when occurring in raw water when compared to sterilized water. In seawater 


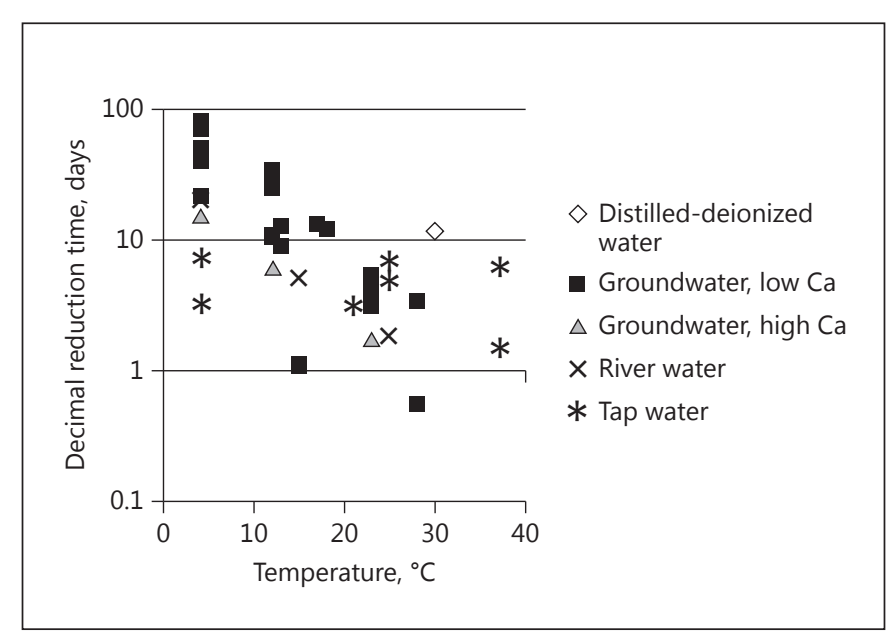

Fig. 1. Decimal reduction times (D1) versus temperature, based on the data from Table 1.

sterilized by autoclaving, boiling, or filtration, an antiviral activity against poliovirus was suppressed; the addition of antibiotics to water had the same effect [17]. Duck plague virus lost $1 \log$ unit in 2 months in filtered lake water, whereas it lost $4 \log$ units in 40 days in unfiltered water [34]. Infectious hematopoietic necrosis virus remained stable for at least 5 days in sterile seawater at $8-12^{\circ} \mathrm{C}$, but lost $5 \log$ units in the same time in raw water [32]. In nonsterile tap water, the inactivation of avian reoviruses was approximately 4 times faster than in sterile tap water [35].

The presence of organic matter in water has a positive impact on virus survival. In mineral water, inactivation of poliovirus or hepatitis A virus was increased when the protein concentration was lower [18]. HIV inactivation in dechlorinated tap water was temporarily slowed by the addition of human serum [25]. The persistence of viral hemorrhagic septicemia virus in seawater was related to the concentration of ovarian fluid (released by herring spawning) in the water: a higher concentration corresponded to a longer stability of the virus [36].

Other factors responsible for increased viral inactivation include the presence of disinfectants such as chlorine $[6,12,22,37]$, extreme $\mathrm{pH}[20,37]$, copper [37], or aeration [32]. The impacts of some factors, such as water hardness, are less firmly proven [3].

Inactivation curves are often used to calculate decay rates or inactivation times, i.e., the time required to obtain a given log-reduction in the viral count. However, what may be considered as the next step in data analysis is lacking: modelling the evolution of inactivation times with temperature would allow for the simulation of values at untested temperatures by interpolation (which should include prediction confidence intervals). This "secondary modelling" is common in predictive microbiology models of bacterial inactivation, but seems much less frequent in viral inactivation studies [38]. It is therefore tempting to use this approach over several studies to obtain a synthesis of results and a general evaluation of the impact of temperature on a given virus. Such an analysis was performed on the impact of temperature on MS2 bacteriophage, which is one of the most studied viruses. From inactivation kinetics available in articles, an inactivation model was applied. The shape was a monophasic log-linear model or, when required, a biphasic model (see Mechanisms of Virus Resistance, below). Decimal reduction times $D$ were calculated for each case: $D$ is defined as the time needed to obtain a 1-log reduction in viral count. In the case of biphasic models, 2 values of $D$ were evaluated, corresponding to the successive slopes of the inactivation kinetics. In this case, the time point at which the first slope ended and the second one begun was evaluated as $t 2$. This model is basically equivalent to the one used by other authors $[11,39]$. These values are presented in Table 1. Temperature is not the only influential factor in the reported data: water type, sterility, or calcium hardness are important parameters. A graphical summary of data in Table 1 is presented in Figure 1, including only the first $D$ for biphasic curves (D1 values). As evidenced by groundwater or river data, a linear relationship exists between temperature and decimal reduction time. This does not appear, however, for tap water data: unknown parameters are likely to have an influence on the decimal reduction time. Such an approach may therefore be useful in having a greater understanding of the viral behavior over a full range of variation of a given factor, but it requires a precise description of all conditions that may influence the virus.

\section{Mechanisms of Virus Inactivation}

The basic structure of viruses includes a genome (single- or double-stranded RNA or DNA), a protein capsid, and sometimes an envelope. This means that viral inactivation is linked to alteration of one of these elements by an environmental stress. The proteins and lipids of the envelope may be disrupted more easily than the other parts of the virus. Thus, naked viruses are generally more resistant than enveloped viruses to similar adverse conditions [22]. Mortality rates of phages infecting Escherichia coli were found to be influenced mostly by the density of genomes and the capsid thickness [40]. 
Table 1. Inactivation kinetics of MS2 as influenced by temperature

\begin{tabular}{|c|c|c|c|c|c|c|c|c|c|c|}
\hline Reference & Water & Sterility & Aeration & Light & $\mathrm{Ca}, \mathrm{mg} / \mathrm{L}$ & $\mathrm{Cl}, \mathrm{ppm}$ & $\mathrm{T},{ }^{\circ} \mathrm{C}$ & $D 1$, days & $t 2$, days & D2, days \\
\hline \multirow[t]{15}{*}{3} & Groundwater & Raw & Aerobic & Unk & 208 & 0 & 4 & 50.0 & & \\
\hline & Groundwater & Raw & Aerobic & Unk & 208 & 0 & 12 & 10.8 & & \\
\hline & Groundwater & Raw & Aerobic & Unk & 600 & 0 & 4 & 15.6 & & \\
\hline & Groundwater & Raw & Aerobic & Unk & 600 & 0 & 12 & 6.17 & & \\
\hline & Groundwater & Raw & Aerobic & Unk & 600 & 0 & 23 & 1.73 & & \\
\hline & Groundwater & Raw & Aerobic & Unk & 138 & 0 & 12 & 33.3 & & \\
\hline & Groundwater & Raw & Aerobic & Unk & 138 & 0 & 23 & 5.35 & & \\
\hline & Groundwater & Raw & Aerobic & Unk & 100 & 0 & 4 & 83.3 & & \\
\hline & Groundwater & Raw & Aerobic & Unk & 100 & 0 & 12 & 10.5 & & \\
\hline & Groundwater & Raw & Aerobic & Unk & 100 & 0 & 23 & 3.82 & & \\
\hline & Groundwater & Raw & Aerobic & Unk & 92 & 0 & 4 & 40.0 & & \\
\hline & Groundwater & Raw & Aerobic & Unk & 224 & 0 & 13 & 13.0 & & \\
\hline & Groundwater & Raw & Aerobic & Unk & 354 & 0 & 13 & 8.77 & & \\
\hline & Groundwater & Raw & Aerobic & Unk & 216 & 0 & 18 & 12.2 & & \\
\hline & Groundwater & Raw & Aerobic & Unk & 216 & 0 & 17 & 13.3 & & \\
\hline \multirow[t]{3}{*}{8} & Groundwater & Raw & Aerobic & Unk & Unk & 0 & 28 & 0.541 & & \\
\hline & Groundwater & Raw & Aerobic & Unk & Unk & 0 & 15 & 1.10 & & \\
\hline & Groundwater & Raw & Anoxic & Unk & Unk & 0 & 28 & 3.41 & & \\
\hline \multirow[t]{3}{*}{26} & Tap water & Sterile & Aerobic & Unk & Unk & 0 & 4 & 3.32 & 1.58 & 14.4 \\
\hline & Tap water & Sterile & Aerobic & Unk & Unk & 0 & 25 & 4.98 & 1.23 & 18.0 \\
\hline & Tap water & Sterile & Aerobic & Unk & Unk & 0 & 37 & 1.52 & & \\
\hline 14 & Groundwater & Raw & Aerobic & Dark & 80 & 0 & 15 & 1.07 & 6.50 & 27.8 \\
\hline \multirow[t]{3}{*}{28} & River water & Raw & Aerobic & Unk & Unk & 0 & 4 & 20.6 & & \\
\hline & River water & Raw & Aerobic & Unk & Unk & 0 & 15 & 5.25 & & \\
\hline & River water & Raw & Aerobic & Unk & Unk & 0 & 25 & 1.87 & & \\
\hline
\end{tabular}

Increased temperature is the main factor affecting virus survival in the environment, through protein denaturation, damage to nucleic acid, or capsid dissociation [29]. Virus inactivation also seems to be correlated to dissolved oxygen, and increased capsid oxidation has been proposed as an explanation [8]. Studies on influenza virus $\mathrm{H} 5 \mathrm{~N} 1$ indicated that acidic $\mathrm{pH}$ affects hemagglutinin (HA surface protein), which is involved in fusion of the viral membrane with the host membrane [20, 41]. In this case, different subtypes carrying different $\mathrm{HA}$ would then have different stabilities in relation to the $\mathrm{pH}$. Such differences in HA stability could be explained by their tertiary structures [41]. Surface charges of viruses vary according to the $\mathrm{pH}$ : most viruses have a negative charge above a certain threshold $\mathrm{pH}$ value (5 for enteric viruses), and a positive one below [2]. Further studies have shown 
that the lipidic envelope of influenza virus can be disrupted by detergents or $\mathrm{OH}^{-}$radicals, thus influencing viral inactivation [20].

Sunlight activity against viruses such as norovirus and bacteriophage GA has been attributed to damage to nucleic acids through the formation of pyrimidine dimers or other products, although other mechanisms may be involved, such as the excitation of active substances present in the capsid or in the environment [9]. In some cases, viral RNA of influenza virus H1N1 was more stable than the viral infectivity, which indicates that the RNA may be protected from environmental stresses: ribonucleoproteins may protect the molecule [21]. Thus, the loss of infectivity would be linked to external structures instead of RNA. This was confirmed by studies on potato spindle tuber viroid, the extended survival of which compared to potato and tomato viruses was attributed to the absence of the proteinbased capsid, which degrades faster than RNA [42]. However, other studies have shown that hepatitis A virus antigen could be detected for longer than the infectious titer of the virus in mineral water [18], which could be interpreted as an indication that the loss of infectivity was mostly due to damage to the viral RNA, rather than capsid damage. However, another reason for this observation could be that the damaged protein retained antigenicity.

Studies have pointed at evidence of an antiviral activity in water that seemed to have a biological origin. Indeed, it was shown that this activity against poliovirus in seawater was suppressed after heating [27]. The absence of microorganisms has been proposed as a possible explanation for slower inactivation of hepatitis A virus and poliovirus in filtered mineral water, as compared to other waters [18]. Bacterial production of proteolytic enzymes has been suggested as a mechanism for the antiviral activity of bacteria [43]; since an increased oxygen level in water or higher temperatures would increase the metabolic activity of bacteria and bacterial enzymes, these factors are linked to viral inactivation $[8,28]$.

\section{Mechanisms of Virus Resistance}

A major phenomenon in viral resistance to adverse environmental conditions is aggregation. Several works have shown that viral particles form aggregates in liquid suspension. Galasso and Sharp [44] studied the inactivation of vaccinia virus by UV light, and found that only $21 \%$ of viruses were present as isolated particles, the rest forming groups from 2 to 80 particles. The frequency of a group was inversely proportional to its size. Their results showed that isolated particles were much easier to destroy than groups: in a population with severe aggregation, the inactivation rate was much slower than in a population with no aggregation. In an experiment involving drinking water, $80 \%$ of poliovirus units exiting their host cells were inside aggregates, pointing to the fact that the majority of viruses in water may exist in an aggregated state [45]. In water, aggregates may form spontaneously from Brownian movement, or from nucleation on aquatic particles. Aggregation may be mistaken for inactivation; furthermore, in laboratory studies, viruses may adhere to the surface of the container [19]. These authors found that in groundwater held at $20^{\circ} \mathrm{C}$ inside a polypropylene container, a significant amount (1.5 log unit) of poliovirus was transferred to the hydrophobic walls in the first 20 days. Within the same time, viral inactivation was estimated to be between 0.38 and $0.64 \log$ unit, while viral aggregation accounted for 1.5 $\log$ unit in the decrease of viral titer. Adhesion and aggregation are influenced by environmental factors: a low $\mathrm{pH}$ (below the isoelectric point) will promote adhesion, as will the presence of divalent ions in the medium; conversely, organic matter in the medium may compete with viruses for adsorption on surfaces [19]. Since such phenomena are reversible, viruses may be released later and thus need to be accounted for to evaluate the infectious risk.

A related phenomenon is the adhesion of viruses to organic particles present in the medium. These particles shield the virus from antiviral agents by offering physical protection: the virucidal activity of disinfectants depends on their ability to reach the virus. Other possible mechanisms include a demand for disinfectants from organic substances, thus diminishing the fraction of active substance that is available to kill the virus $[2,37]$. Likewise, sediments play a role as reservoirs for viruses [2].

Viruses may be protected from environmental adverse effects when they are inside structures such as fungal spores or seeds [46]. Likewise, amoebas have been shown to carry viruses such as adenovirus, mimivirus [47], murine norovirus, and others [48]. Although the viral population will decrease by a small amount once internalized, viruses are able to survive inside amoebas, even as cysts, for several days [48]. Amoebas will thus shield viruses from external harm; amoebas themselves are furthermore able to be protected, for example inside biofilms or as cysts.

Influenza viruses, which have a lipid envelope, have been shown to survive well when exposed to freezing and thawing cycles: the envelope of some viruses solidifies from an oily substance to a hardened gel when the temperature decreases [1]. If viruses are able to survive freezing temperatures, ice may offer them protection from the 
environment, such as a reduced penetration of UV. The nature of the envelope, which comes from the cellular host of the virus, also plays a role in their survival: influenza viruses released from mammalian cells were shown to have significantly higher survival in water at $35^{\circ} \mathrm{C}$ than viruses released from avian cells [49].

Inactivation kinetics of viruses are often summarized using a log-linear relationship, assuming that the log of the viral population decreases linearly with time. This relationship is then described using the following equation:

$$
N=N_{0} \times e^{-k t},
$$

where $N$ is the viral population at time $t, N_{0}$ is the initial viral population, and $k$ is the inactivation rate. This equation is often used to evaluate a value summarizing the inactivation curve, such as the time required to obtain a given log-reduction (generally 1 or 3 log units, corresponding to a 90 or $99.9 \%$ reduction, respectively). While this value should be extremely useful in comparing studies, it requires that the shape of the inactivation curve is indeed log-linear. This is however not always the case. Other shapes exist: inactivation curves may for example exhibit an initial shoulder, or a tailing effect. A shoulder corresponds to a viral population that is initially stable, before the actual reduction in the viral population begins. A tailing effect is a decrease in the slope of the inactivation curve, indicating that the last survivors of the viral population appear more resistant than the general population at the start of the inactivation; this may be described using a second-order equation, with 2 successive inactivation rates [11]. These shapes have long been known and described, as discussed by Hiatt [39]. However, many authors choose the more simple approach of a log-linear first order curve. Using this simplifying assumption while its validity is not proven (or even patently invalid) may produce estimates that are highly biased.

\section{Conclusions and Perspectives}

Studies on virus survival in water use a great diversity of methods. Water types, viruses, and factors of influence are also highly variable across reports. As a result, quantitative comparison between studies and meta-analyses are difficult, or even impossible. It is therefore generally more interesting to focus on the isolated impact of one or several factors within one study, with all other sources of influence being fixed at a given value.

However, it is possible to observe general trends. Qualitatively, virus survival is challenged by increasing tem- perature, stronger sunlight, higher bacterial concentration, or the presence of disinfecting substances. Conversely, when viruses are able to form aggregates, to adhere to particles or surfaces, or to be internalized in living organisms, they will resist adverse environmental conditions.

Virological studies are obviously complicated and costly. Since one laboratory will not be able to test all interesting conditions, it is desirable to compare studies obtained from various researchers. To increase this possibility, it may be useful to consider the following suggestions. When obtaining inactivation kinetics, experimenters should account for the real shape of the curve, including an initial shoulder if present, the rate of decrease or decimal reduction time, and a second rate of decrease if a biphasic curve is observed [39]. The limit of quantification, and possibly the limit of detection, should be reported to analyze inactivation curves. In the case of the evaluation of a factor's impact, it may be useful, for interstudy comparison purposes, to include a standardized, controlled medium as a reference; for example, distilled, demineralized, sterile water could be included in parallel with the medium of interest $[21,22,49]$. Precise knowledge of factors influencing virus survival should be available by reporting not only the varying factors of the experimental design, but also the surrounding conditions, such as illumination, aeration, and microbial concentration, etc. In order to produce exploitable kinetics, a sufficient number of data points are required across the duration of the experiment. It is therefore necessary to take into account the time scale given the probable impact of the factor level.

The loss and possible recovery of infectivity caused by different factors may then be evaluated in the laboratory, with the inclusion of reference conditions and complete inactivation curves (possibly including modelling) allowing for comparison between experimental results across laboratories.

Aside from these laboratory tests, larger scale studies are needed [33]. Few authors have addressed the detection of real viruses in real environments over long periods [50]. Such results would be helpful in assessing the persistence of virus infectivity in the environment $[51,52]$. Interactions of viruses with other microorganisms (infection targets, protective hosts, etc.) also represent an interesting prospect.

\section{Disclosure Statement}

The authors have no conflicts of interest to declare. 


\section{References}

1 Shoham D, Jahangir A, Ruenphet S, Takehara $\mathrm{K}$ : Persistence of avian influenza viruses in various artificially frozen environmental water types. Influenza Res Treat 2012;2012: 912326.

2 Okoh AI, Sibanda T, Gusha SS: Inadequately treated wastewater as a source of human enteric viruses in the environment. Int J Environ Res Public Health 2010;7:2620-2637.

3 Yates MV, Gerba CP, Kelley LM: Virus persistence in groundwater. Appl Environ Microbiol 1985;49:778-781.

4 Ford TE: Microbiological safety of drinking water: United States and global perspectives. Environ Health Perspect 1999;107:191-206.

5 Barna Z, Kádár M: The risk of contracting infectious diseases in public swimming pools. A review. Ann Ist Super Sanità 2012;48:374386.

6 Wade MM, Chambers AE, Insalaco JM, Zulich AW: Survival of viral biowarfare agents in disinfected waters. Int J Microbiol 2010;2010: 412694.

7 Pereira C, Silva YJ, Santos AL, Cunha A, Gomes NC, Almeida A: Bacteriophages with potential for inactivation of fish pathogenic bacteria: survival, host specificity and effect on bacterial community structure. Marine Drugs 2011;9:2236-2255.

8 Gordon C, Toze S: Influence of groundwater characteristics on the survival of enteric viruses. J Appl Microbiol 2003;95:536-544.

9 Flannery J, Rajko-Nenow P, Keaveney S, O’Flaherty V, Doré W: Simulated sunlight inactivation of norovirus and FRNA bacteriophage in seawater. J Appl Microbiol 2013;115: 915-922.

10 Ngazoa ES, Fliss I, Jean J: Quantitative study of persistence of human norovirus genome in water using TaqMan real-time RT-PCR. J Appl Microbiol 2008;104:707-715.

11 Charles KJ, Shore J, Sellwood J, Laverick M, Hart A, Pedley S: Assessment of the stability of human viruses and coliphage in groundwater by PCR and infectivity methods. J Appl Microbiol 2009;106:1827-1837.

12 Allwood PB, Malik YS, Maherchandani S, Hedberg CW, Goyal SM: Effect of temperature on the survival of F-specific RNA coliphage, feline calicivirus, and Escherichia coli in chlorinated water. Int J Environ Res Public Health 2005;2:442-446.

13 Fallahi S, Mattison K: Evaluation of murine norovirus persistence in environments relevant to food production and processing. J Food Prot 2011;74:1847-1851.

14 Ogorzaly L, Bertrand I, Paris M, Maul A, Gantzer C: Occurrence, survival, and persistence of human adenoviruses and F-specific RNA phages in raw groundwater. Appl Environ Microbiol 2010;76:8019-8025.
15 Bae S, Wuertz S: Survival of host-associated bacteroidales cells and their relationship with Enterococcus spp., Campylobacter jejuni, Salmonella enterica serovar Typhimurium, and adenovirus in freshwater microcosms as measured by propidium monoazide-quantitative PCR. Appl Environ Microbiol 2012;78:922932.

16 Hill WF Jr, Hamblet FE, Akin EW: Survival of poliovirus in flowing turbid seawater treated with ultraviolet light. Appl Microbiol 1967; 15:533-536.

17 Fujioka RS, Loh PC, Lau LS: Survival of human enteroviruses in the Hawaiian ocean environment: evidence for virus-inactivating microorganisms. Appl Environ Microbiol 1980;39:1105-1110.

18 Biziagos E, Passagot J, Crance JM, Deloince R: Long-term survival of hepatitis A virus and poliovirus type 1 in mineral water. Appl Environ Microbiol 1988;54:2705-2710.

19 Gassilloud B, Gantzer C: Adhesion-aggregation and inactivation of Poliovirus 1 in groundwater stored in a hydrophobic container. Appl Environ Microbiol 2005;71:912920.

20 Shahid MA, Abubakar M, Hameed S, Hassan S: Avian influenza virus $\left(\mathrm{H}_{5} \mathrm{~N}_{1}\right)$; effects of physico-chemical factors on its survival. Virol J 2009;6:38

21 Dublineau A, Batéjat C, Pinon A, Burguière AM, Leclercq I, Manuguerra JC: Persistence of the 2009 pandemic influenza A (H1N1) virus in water and on non-porous surface. PLoS One 2011;6:e28043.

22 Fitzgibbon JE, Sagripanti JL: Analysis of the survival of Venezuelan equine encephalomyelitis virus and possible viral simulants in liquid suspensions. J Appl Microbiol 2008;105: 1477-1483.

23 Lo S, Gilbert J, Hetrick F: Stability of human enteroviruses in estuarine and marine waters. Appl Environ Microbiol 1976;32:245-249.

24 Silverman AI, Nguyen MT, Schilling IE, Wenk J, Nelson KL: Sunlight inactivation of viruses in open-water unit process treatment wetlands: modeling endogenous and exogenous inactivation rates. Environ Sci Technol 2015;49:2757-2766.

25 Moore BE: Survival of human immunodeficiency virus (HIV), HIV-infected lymphocytes, and poliovirus in water. Appl Environ Microbiol 1993;59:1437-1443.

26 Allwood PB, Malik YS, Hedberg CW, Goyal SM: Survival of F-specific RNA coliphage, feline calicivirus, and Escherichia coli in water: a comparative study. Appl Environ Microbiol 2003;69:5707-5710.

27 Akin EW, Hill WF Jr, Clarke NA: Mortality of enteric viruses in marine and other waters; in Gameson ALH (ed): Discharge of Sewage from Sea Outfalls. Elmsford, Pergamon Press, 1975.
28 Yang Y, Griffiths MW: Comparative persistence of subgroups of F-specific RNA phages in river water. Appl Environ Microbiol 2013; 79:4564-4567.

29 Paluszak Z, Lipowski A, Ligocka A: Survival rate of Suid herpesvirus (SuHV-1, Aujeszky's disease virus, $\mathrm{ADV}$ ) in composted sewage sludge. Pol J Vet Sci 2012;15:51-54.

30 Abad FX, Pintó RM, Villena C, Gajardo R, Bosch A: Astrovirus survival in drinking water. Appl Environ Microbiol 1997;63:31193122.

31 Mihai ME, Tecu C, Ivanciuc AE, Necula G, Lupulescu E, Onu A: Survival of H5N1 influenza virus in water and its inactivation by chemical methods. Roum Arch Microbiol Immunol 2011;70:78-84.

32 Garver KA, Mahony AA, Stucchi D, Richard J, van Woensel C, Foreman M: Estimation of parameters influencing waterborne transmission of infectious hematopoietic necrosis virus (IHNV) in Atlantic salmon (Salmo salar). PLoS One 2013;8:e.82296.

33 Rzezutka A, Cook N: Survival of human enteric viruses in the environment and food. FEMS Microbiol Rev 2004;28:441-453.

34 Wolf K, Burke CN: Survival of duck plague virus in water from Lake Andes National Wildlife Refuge, South Dakota. J Wildl Dis 1982;18:437-440

35 Mor SK, Verma H, Sharafeldin TA, Porter RE, Ziegler AF, Noll SL, Goyal SM: Survival of turkey arthritis reovirus in poultry litter and drinking water. Poult Sci 2015;94:639-642.

36 Kocan RM, Hershberger PK, Elder NE: Survival of the North American strain of viral hemorrhagic septicemia virus (VHSV) in filtered seawater and seawater containing ovarian fluid, crude oil and serum-enriched culture medium. Dis Aquat Organ 2001;44:7578.

37 Jordan FTW, Nassar TJ: The survival of infectious bronchitis (IB) virus in water. Avian Pathol 1973;2:91-101.

38 Deboosere N, Pinon A, Delobel A, Temmam S, Morin T, Merle G, Blaise-Boisseau S, Perelle S, Vialette M: A predictive microbiology approach for thermal inactivation of Hepatitis A virus in acidified berries. Food Microbiol 2010;27:962-967.

39 Hiatt CW: Kinetics of the inactivation of viruses. Bacteriol Rev 1964;28:150-163.

40 De Paepe M, Taddei F: Viruses' life history: towards a mechanistic basis of a trade-off between survival and reproduction among phages. PLoS Biol 2006;4:e193.

41 Sawoo O, Dublineau A, Batéjat C, Zhou P, Manuguerra J-C, Leclercq I: Cleavage of hemagglutinin-bearing lentiviral pseudotypes and their use in the study of influenza virus persistence. PLoS One 2014;9:e106192. 
42 Mehle N, Gutiérrez-Aguirre I, Prezelj N, Delic D, Vidic U, Ravnikar M: Survival and transmission of potato virus $\mathrm{Y}$, pepino mosaic virus, and potato spindle tuber viroid in water. Appl Environ Microbiol 2014;80:1455-1462.

43 Hawley LM, Garver KA: Stability of viral hemorrhagic septicemia virus (VHSV) in freshwater and seawater at various temperatures. Dis Aquat Organ 2008;82:171-178.

44 Galasso GJ, Sharp DG: Effect of particle aggregation on the survival of irradiated vaccinia virus. J Bacteriol 1965;90:1138-1142.

45 Young DC, Sharp DG: Poliovirus aggregates and their survival in water. Appl Environ Microbiol 1977;33:168-177.

46 Mehle N, Ravnikar M: Plant viruses in aqueous environment - survival, water mediated transmission and detection. Water Res 2012; 46:4902-4917.
47 Cateau E, Delafont V, Hechard Y, Rodier MH: Free-living amoebae: what part do they play in healthcare-associated infections? J Hosp Infect 2014;87:131-140.

48 Hsueh TY, Gibson KE: Interactions between human norovirus surrogates and Acanthamoeba spp. Appl Environ Microbiol 2015;81: 4005-4013.

49 Shigematsu S, Dublineau A, Sawoo O, Batéjat C, Matsuyama T, Leclercq I, Manuguerra J-C: Influenza A virus survival in water is influenced by the origin species of the host cell. Influenza Other Respir Viruses 2014;8:123130.

50 Foreman MG, Guo M, Garver KA, Stucchi D, Chandler P, Wan D, Morrison J, Tuele D: Modelling infectious hematopoietic necrosis virus dispersion from marine salmon farms in the Discovery Islands, British Columbia, Canada. PLoS One 2015;10:e0130951.
51 Malham SK, Rajko-Nenow P, Howlett E, Tuson KE, Perkins TL, Pallett DW, Wang H, Jago CF, Jones DL, McDonald JE: The interaction of human microbial pathogens, particulate material and nutrients in estuarine environments and their impacts on recreational and shellfish waters. Environ Sci Processes Impacts 2014;16:2145-2155.

52 Parkinson AJ, Evengard B, Semenza JC, Ogden N, Børresen ML, Berner J, Brubaker M, Sjöstedt A, Evander M, Hondula DM, Menne B, Pshenichnaya N, Gounder P, Larose T, Revich B, Hueffer K, Albihn A: Climate change and infectious diseases in the Arctic: establishment of a circumpolar working group. Int J Circumpolar Health 2014;73: 25163. 